\title{
The Addis Ababa Declaration to end infant oral mutilation
}

Valerie Wordley' and Raman Bedi*2

\section{Key points}

Reiterates the practice of infant oral mutilation (IOM) as a dangerous practice affecting millions of

\section{Abstract}

In 2019, chief dental officers from Ethiopia, Somalia, Kenya, Tanzania, Rwanda, Democratic Republic of Congo and Sudan attended the inaugural End Infant Oral Mutilation Conference in Addis Ababa, Ethiopia. The subsequent Addis Ababa Declaration has launched a public health action programme across the continent, aiming to impact over 100 million people in 5 years.

On 17-19 June 2019 chief dental officers from East \& Central Africa (Ethiopia, Somalia, Kenya, Tanzania, Rwanda, Democratic Republic of Congo and Sudan) convened in Addis Ababa to strategise how to end the barbaric practice of infant oral mutilation (IOM) within 10 years.

IOM is an alarming traditional practice executed upon young infants suffering from diarrhoea and fever as an ignorant means of preventing these conditions. Commonly performed in East and Central African countries by local healers, it involves the barbaric gouging out of unerupted baby canine teeth whereby the swollen gums containing the developing tooth buds are mistaken for 'tooth worms.' ${ }^{1}$

As the authors have previously written, IOM is highly dangerous and sometimes fatal. ${ }^{2}$ The blood loss and shock borne from the rudimentary surgery often leads to anaemia, while the poor infection control involved exposes the child to an extremely high risk of septicaemia, tetanus and transmission of

${ }^{1}$ Consultant, Global Child Dental Fund, Surrey Street, Norfolk Building, Rooms G03G03A, London WC2R 2ND; ${ }^{2}$ Emeritus Professor - King's College London; Chairman of Global Child Dental Fund, Global Child Dental Fund, Surrey Street, Norfolk Building, Rooms G03G03A, London WC2R 2ND

${ }^{*}$ Correspondence to: Raman Bedi

Email: raman.bedi@kcl.ac.uk

Refereed Paper.

Accepted 30 July 2019

https://doi.org/10.1038/s41415-019-0891-5

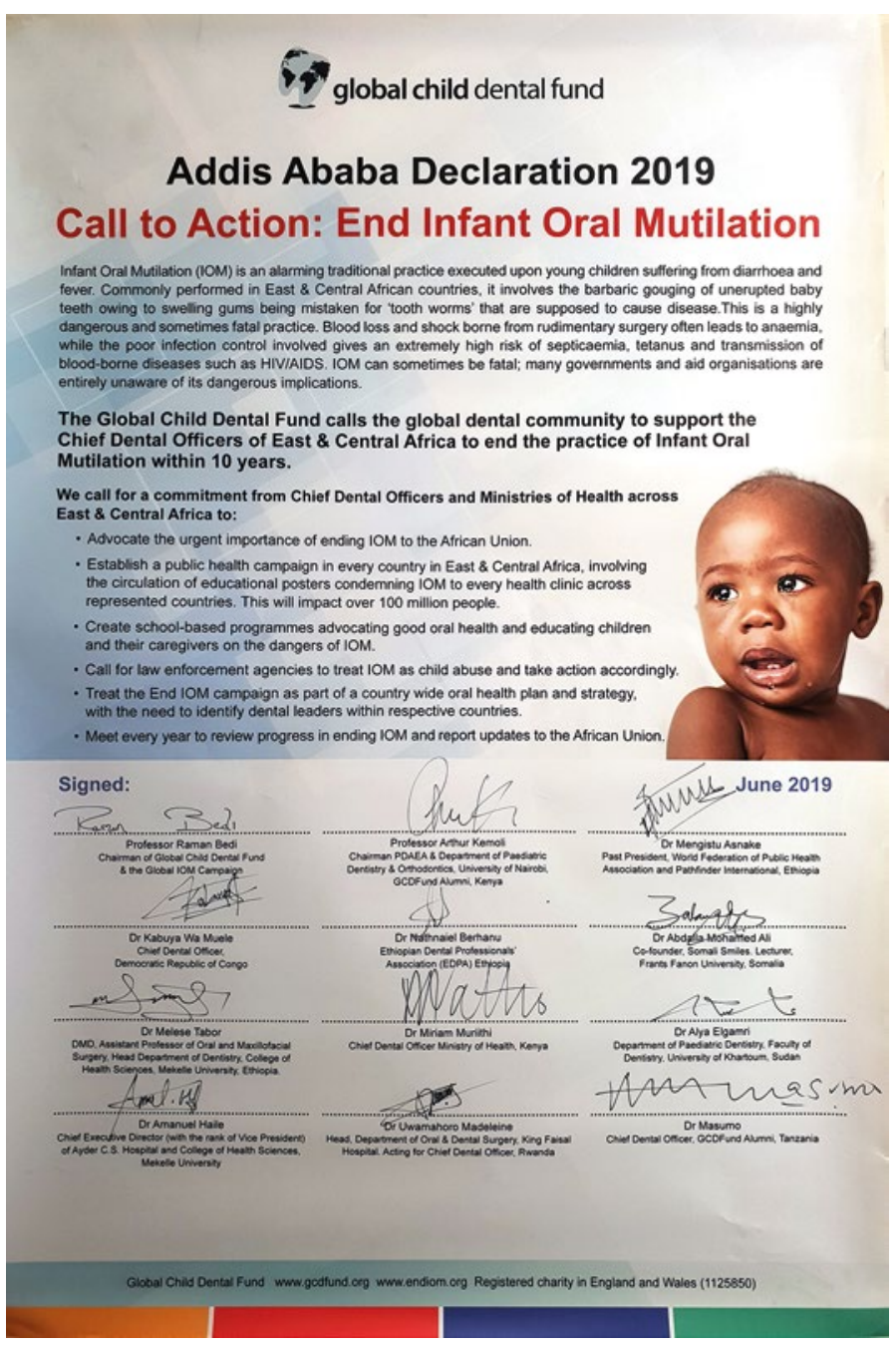

Fig. 1 Addis Ababa Declaration 2019 
- Treat the End IOM campaign as part of a

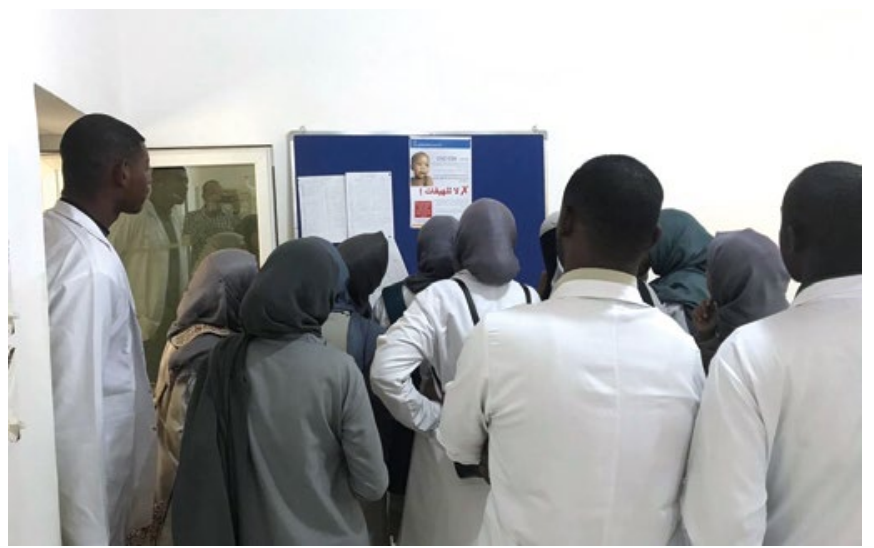

Fig. 2 Students and dentists learning about IOM at the Khartoum Dental Teaching Hospital

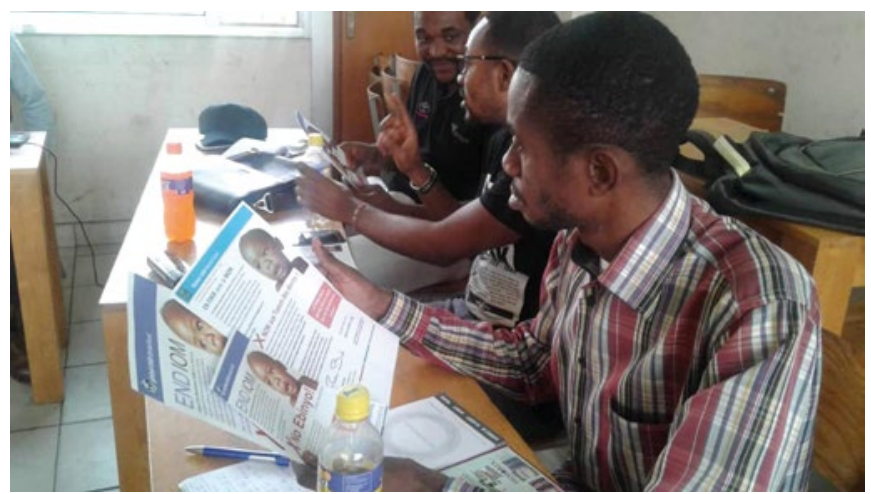

Fig. 3 Primary care workers being trained to educate mothers against IOM in the Democratic Republic of Congo

blood-borne diseases such as hepatitis B and HIV/AIDS. Many children have died and are still dying to this day from the effects of IOM. ${ }^{3,4}$

Delegates in Addis Ababa agreed unanimously that IOM is the largest form of child abuse in the dental field. While some are of the opinion that IOM should not be eradicated because it is a 'cultural habit', the authors argue that IOM is indeed a form of child abuse because firstly there is absolutely no benefit to the practice (conversely, it is extremely dangerous) and, secondly, other acceptable cultural beliefs and habits observed across communities worldwide are carried out in adults who are fully capable of consent. To this end, chief dental officers discussed and pledged to investigate legal frameworks in their countries. For example, in Ethiopia, IOM is not illegal per se unless a child dies as a consequence. There is a need for much greater clarity on this issue.
Based on discussions during the conference, the 2019 Addis Ababa Declaration was formulated and signed by chief dental officers from all countries attending (Fig. 1). The Declaration calls for all stakeholders within and around the region to:

- Advocate the urgent importance of ending IOM to the African Union

- Establish a public health campaign in every country in East \& Central Africa, involving the circulation of educational posters condemning IOM to every health clinic across represented countries. This will impact over 100 million people in 5 years

- Create school-based programmes advocating good oral health and educating children and their caregivers on the dangers of IOM

- Call for law enforcement agencies to treat IOM as child abuse and take action accordingly country wide oral health plan and strategy, with the need to identify dental leaders within respective countries

- Meet yearly to review progress in ending IOM and report updates to the African Union.

Chief Dental Officers who attended the Addis Ababa conference are currently focusing on distributing educational IOM prevention posters across every health clinic in their jurisdictions. These posters use the terminology of IOM in several local languages. Figure 2 shows students and dentists learning about IOM at the Khartoum Dental Teaching Hospital. This is the largest governmental dental hospital in Sudan. Figure 3 depicts primary care workers being trained to educate mothers against IOM in the Democratic Republic of Congo (DRC). This followed a national oral health meeting in DRC discussing elimination of IOM at national level. These public health campaigns across East and Central Africa will begin to raise awareness of the harmful practice of IOM aimed at both adult and child audiences.

Ultimately, we are working towards the African Union condemning the dangerous practice of IOM in all member states. Spreading knowledge about this barbaric practice among dental professionals across the world will help create unity and build meaningful collaborations in ending IOM. To help spread awareness in your dental school or clinic, please visit and download our presentation from: https://www.gcdfund.org/our-work/ eradicate-infant-oral-mutilation-iom

\section{References}

1. Kemoli A M. Raising the awareness of infant oral mutilation myths and facts. Contemp Clin Dent 2015; 6 (Suppl S2): 137-138.

2. Wordley V, Bedi R. Infant oral mutilation in East Africa: Eradication within 10 years. Br Dent J 2019; 226: 14-15. DOI: 10.1038/sj.bdj.2019.1.

3. Jamieson L M. Using qualitative methodology to elucidate themes for a traditional tooth gauging education tool for use in a remote Ugandan community. Health Educ Res 2006; 21: 477-487. DOI: 10.1093/her/cyh073.

4. Edwards P C, Levering N, Wetzel E, Saini T. Extirpation of the primary canine tooth follicles: a form of infant oral mutilation. J Am Dent Assoc 2008; 139: 442-450. DOI: 10.14219/jada.archive.2008.0187. 